\title{
INTERVIEW WITH Ruth ROSENGARTEN. "FEMINIST PHOTOGRAPHY TODAY IS DIVERSE AND FAIRLY ELASTIC, RATHER THAN FIXATED ON THE OLD BINARIES"
}

\author{
Maria da Luz Correia \& Carla Cerqueira
}

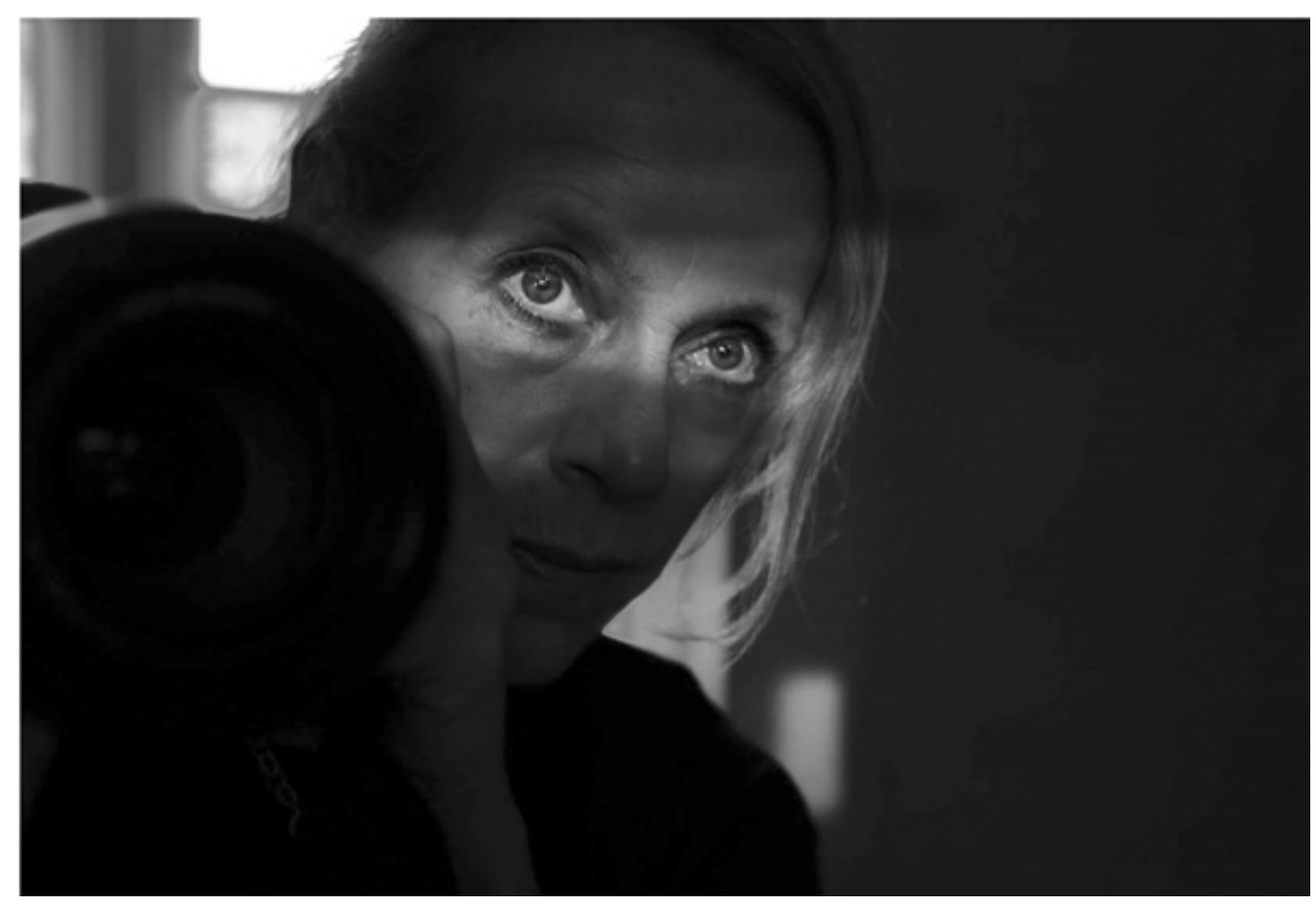

Figure 1: Self, Ruth Rosengarten, 2013 Source: http://ruthrosengarten.com/

It all started with the article "Points of View: Photography and Feminism in the context of Postmodernism" that we found casually in an old issue of Communication and Languages journal, dated from 1988. Ruth Rosengarten was the author of this essay and we were already familiar with her work Contrary, Crush, Love the Family and the New State regime in the work of Paula Rego, edited by Assírio \& Alvim in 2009. The researcher, artist and curator, Ph.D. in Art History from the Courtauld Institute of Art at the University of London, was born in Israel, lived in Johannesburg, London and Lisbon, and most recently settled in a small village in Cambridgeshire, UK. It was somewhere between Cambridgeshire and Braga that, a few months ago, two decades after her pioneering essay on photographic practice and feminist theory, we spoke with Ruth Rosengarten by videoconference, posing a number of questions around the intersection between photography and gender'.

\footnotetext{
' It should be noted that the questions and answers reproduced here, although they result largely from this conversation, were later exchanged with the interviewee, edited and translated into Portuguese.
} 
Maria da Luz Correia \& Carla Cerqueira - One of your first essays is about photography and feminism. To be more precise, about the role of feminist theory and photographic practice in the critique of hegemonic authority and in the detraction of representation. What has changed since then? What do you mean when you report to your work as guided by "feminist lenses"?

Ruth Rosengarten - That essay was written in the 1980s - I was very young, and these were really fairly early days in conversations about post-modernism and representation, as well as feminism and representation, hybridity, multiculturalism in relation to the arts. I think that there is as urgent a need for feminism today as there was then, but it's perhaps shifted to other areas, different contexts. When I look at that essay today, I can see where I was coming from, but I hope my writing today about this topic might be a little more nuanced, less programmatic or didactic. At the time I wrote this essay, Judith Butler's writing about the performativity of gender - and the whole question of gender fluidity - was only just peeping over the horizon. Performativity is an important ingredient in the discussion of gender today, and in the relationship of gender to the visual arts. Also I think that at the time of that essay, I didn't make a clear distinction between different constituencies of feminism - this became much clearer to me in the 1990s, and was consolidated in my writings on Paula Rego. The feminism of difference (the psychoanalytic model) and the feminism of equality (the Marxist/economicist model) are not always mutually supportive or even conciliatory. There are questions, too, about cultural and class difference that are much more pressing today. I am concerned with equality of opportunity, pay, visibility. I think feminism as a liberatory practice has lent an enabling discourse to other cultural spheres, and continues to do so.

M. L. C. \& C. C. - In this essay, you commented on different feminist photographic works, such as those of Sherrie Levine, Barbara Kruger, Sally Mann, Jo Spence, Holger Trülsch \& Vera Lehndorff, Cindy Sherman... Which feminist photographers would you choose today if you wrote about photography and feminism?

R. R. - Oh that's a great question, with a very long answer. Anyhow, looking back at that piece of writing today, I realise just how centred I was on work within a cultural hegemony: almost all the artists I discuss were American or British. Sherrie Levine and Barbara Kruger's works are not that interesting to me today, but there are important historical figures worthy of mention. Someone like Mary Kelley has, I think, continued to remain historically interesting, as have Cindy Sherman, Jo Spence and Sally Mann, in very different ways. The work of Claude Cahun has come into focus, and remains extremely important - a very early example of the problematisation of gender and its relation to masquerade and performativity.

I would definitely include more performative work too - for instance, although photography was only documentary of Ana Mendieta's performance work, she's a key figure.

Oh and so much more work from all over the world. From India Pushpamala N., who, like Sherman, puts herself into staged images... From Japan, Yasumasa Morimura, who's a man, and whose inclusion, therefore, would be an interesting problematisation 
of gender and feminism. Moroccan artist Latifa Echakhch also rehearses differently gendered identities in a context where the boy/girl difference produces vastly divergent expectations of life experience. In a completely different context, and in a much more muted manner, Finnish photographic artist Elina Brotherus works with the expectations generated by femininity. Then there are photographic artists who work with the idea of gender fluidity, like Catherine Opie, Melody Melamed, Loretta Lux, or Zakary Drucker and Rhys Ernst. Yishay Garbasz, an Israeli transgender/crossover artist working in photography and performance. Zoe Leonard explores questions of feminity and race, as do Carrie Mae Weems and Lorna Simspon, and Cuban photographic artist Maria Magdalena Campos Pons, the Kenyan artist Ingrid Mwangi. Describing herself as a visual activist, South African Zanele Muholi has made a very significant mark with her powerful photographic images exploring race, gender identity and sexual preference. Oh, there are so many others, interesting artists working across the mediums and practices of photography.

M.L.C. \& C.C. - Is there a feminine look in the way of doing and thinking photography? Something that would describe a feminist aesthetic?

R.R. - I'm not sure about this. I would say no to the question "is there a feminine look" - though if there is such a thing as feminism, which there is, I would say there must be a feminist aesthetics. I think that, as in other areas of expression and endeavour, feminist photography today is diverse and fairly elastic, rather than fixated on the old binaries. Androgyny, for once, is one of other characteristics of feminist photographic practice and I mean androgyny not only in a way that describes gender or sexuality, but also as a principle of fluidity and ambiguity.

M.L.C. \& C.C. - How would you define feminism today?

R.R. - For me, feminism today continues to be essential, and two-pronged: about equality, and about difference. And by difference, I mean not only the differences between the genders and the possibility of overriding those differences through varied fluid syntheses, but also differences among women. I think we're much more cautious today than, say, in the 1980s, about not falling into an essentialist trap and about recognising cultural difference. So, feminism means different things in different contexts. There are still countries in which women have to gain so many personal and political liberties, things we now take for granted for example in England, where I live, even if we still have to struggle with glass ceilings at work. Artists from all over the world have been dynamic and innovative in the way they have harnessed different - and frequently critical - forms of visual culture in expressing those different priorities.

M.L.C. \& C.C. - Reading your biography, one gets this impression of a certain nomadism. You've written somewhere that you have never decided what you wanted, "between making things and writing about people who make things". Your work is divided in two institutions, two different worlds: art and academia. You have also moved around quite often, living in different countries: Israel, South Africa, Portugal, England; you had 
a long stay in Australia in the 1990s. This professional and geographic nomadism has pros and cons...

R.R. - Well, I think the cons are perhaps more obvious, or rather, in a context in which people talk a lot about identity and identification and belonging, moving around seems like being suspended, uninvolved, unattached, rootless. It seems that way, and in some ways, it is that way. But to me that is not a negative thing. Quite the opposite. I feel at home in several different places, and at the same time, I feel slightly separate from those places, a kind of un-belonging at some level that is not uncomfortable to me. In place of the stability of roots, I have had the good fortune to have access to different contexts, different languages, different geographies and clusters of people, all of which and all of whom are incredibly important to me.

M. L. C. \& C. C. - Related to your theoretical and artistic approach of photography, the ideas of archive and memory seem very important to you: three years ago, for instance, you commissioned the exhibition Between Memory and Archive at the Berardo Museum in Lisbon...

R. R. - I suppose there is something like a Zeitgeist: in the past couple of decades the question of the archive has come into focus in general and in art practice in particular. Like many artists and academics today, I am interested in the idea of memory, both personal and collective and also in the relationship between memorialisation and the archive. The nexus document-monument is one that abuts on the idea of the archive, or relies upon it, and the exhibition to which you're referred, addressed that issue in relation to works chosen from that particular collection. From family archive to public archive - there are different kinds of archives, but in general, I suppose I'm interested in the grids we use for ordering and tabulating knowledge and information, and from which we retrieve aspects of the past. I've always been fascinated with ordering systems - taxonomies, but not only - and always obsessed with ways of ordering my own papers, the bits and pieces, the reading notes, the personal documents, the photographs, the journal notes: these all require systems in order to render them accessible in the future. The grid - which is another way of saying the filing system - and what it contains, as well as what it lets seep through the categorical cracks, has fascinated me since I can remember. I'm also really interested in the difference between history - which entails a certain narrative an account - and the archive, which is just one of the sources upon which history draws.

M. L. C. \& C. C. - Would you define yourself as an archivist?

R. R. - I suppose like all good archivists, I might define myself as a failed archivist: one is always two steps (or more) behind the perfect system! Indeed, my fascination with archives also means that l've wasted too many hours trying to devise perfect systems for the storage and retrieval of information: that's the personal background to my interest in archives. 
M. L. C. \& C. C. - Going back to your essay of the 1980 s on photography and feminism, there you mentioned the advent of photography as an historical turning point. How do you perceive today the emergence of the digital?

R. R. - Digitisation changes everything. Digital image production and manipulation has radically displaced older practices - and theories - of photography and reshaped their parameters. The advent of the digital era and the proliferation of online photo-sharing platforms it has spawned, has unleashed an unprecedented volume of photographs in public circulation, where the distinctions between amateur, vernacular, documentary and art photography are often blurred. Arguably, this blurring itself is not new but rather, underlines the fact that "photography" was always ever thus: an umbrella term for varieties of activity.

One of the most recurrent motifs in all photographic theory concerns the way photography was historically a technology in the service of empirical truth. The artefact that enables the "pencil of nature"- as Fox-Talbot famously called photography - to manifest itself, has always also been open not only to retouching, but also to staging. But simultaneous to the uses of "photography" that extend those of analogue photography, there are entirely new uses of the image, which - essentially immaterial - can now be bonded onto any conceivable support. This suggests that, as Fred Ritchin argues, "for those who think of digital media as simply providing more efficient tools, what we are witnessing today is an evolution in media".

M. L. C. \& C. C. - In that essay from the 80's, you also mentioned how the specificity of photography was defined by its special contiguity with reality, by its indexicality. The advent of the digital appears also to introduce a rupture regarding this indexical thought...

R. R. - The digital "photograph" loosens that firm link between "the photograph" and the indexical trace. Digital image capture, while simulating photography in some respects, offers a range of technical capabilities that alter this particular relationship of the artefact with the indexical trace and the evidentiary link thus forged with time past. In other words, digitisation has changed the ontological status of "the photograph". The substitution of smooth grain for pixel mosaic - continuous tone imprint for binary codes - is symptomatic of the fact that, strictly speaking, digital images are in no way photographic, since the coded signifiers are abstract data that can easily be played with as abstractions, with no connection to the real. In the digital darkroom inventiveness pits itself against indexicality. While the idea that photography was indexical served as guarantor of the truth effect that distinguished photography from other forms of representation, digital elaboration presses upon the viewer the constructed nature of the image. That's really interesting. And many artists - including feminist "photographers", though not exclusively those, use these to incredibly dynamic and diverse effect.

M. L. C. \& C. C. - Does the digital allow us to abandon the myth of photographic truth?

R.R. - It is important to stress that significant cultural continuities bind the new digital images to old analogue photographs and the habits of viewing they fostered, 
prompting certain expectations on the part of viewers, not least, the prevailing assumption of the validating "truth effect" of photographic work, its privileged relationship with the Real. This persists, for instance, in the ways in which photographic images are used on social media as proof or evidence. Despite the fact that, more than their analogue counterparts, digital images can be altered and "doctored" easily and even radically, the notion that a photograph stands as a shrine to time past continues, in certain quarters, to be pervasive.

\section{Biographical Notes}

Maria da Luz Correia is an Assistant Professor in the Department of Languages, Literatures and Cultures, in the University of Azores and a researcher at Communication and Society Research Centre (CECS). She holds a PHD in Communication Sciences, from the University of Minho and in Sociology, from the Université Paris Descartes - Sorbonne. She has published on the fields of visual culture, image theory and photography.

E-mail: maria.If.correia@uac.pt

Universidade dos Açores, Faculdade de Ciêncais Sociais e Humanas, Ladeira da Mãe de Deus, 9501-855 Ponta Delgada, Portugal

Carla Cerqueira holds a PhD in Communication Sciences (specialization in Communication Psychology). She is a Postdoctoral Grantee in Communication Sciences (SFRH/BPD/86198/2012) at the Communication and Society Research Centre (CECS), University of Minho, Portugal, and a visiting researcher at the Department of Media, Communication and Culture, Autonomous University of Barcelona, Spain; and at the Department of Social Sciences, Erasmus University of Rotterdam, Netherlands. She is also an Assistant Professor at Lusophone University of Porto, Portugal. Author of several books, book chapters and papers in scientific journals, her research interests include gender, feminisms, NGOs and media studies.

E-mail: carlaprec3@gmail.com

Centro de Estudos de Comunicação e Sociedade, Universidade do Minho, Campus de Gualtar, 4710-057 Braga, Portugal

\section{* Submitted: 07-11-2017 \\ * Accepted: 19-11-2017}

